\title{
AVALIAÇÃO DE LINHAGENS DE TRIGO ORIGINÁRIAS DE HIBRIDAÇÃO COM E SEM IRRADIAÇÃO GAMA ${ }^{(1)}$
}

\author{
CARLOS EDUARDO DE OLIVEIRA CAMARGO ${ }^{(2,7)}$; ANTONIO WILSON PENTEADO \\ FERREIRA FILHO $^{(2)}$; AUGUSTO TULMANN NETO ${ }^{(3,7)}$; ARMANDO PETTINELLI JUNIOR ${ }^{(4)}$; \\ JAIRO LOPES DE CASTRO ${ }^{(5)}$; JOÃO CARLOS FELICIO ${ }^{(2)}$; \\ JÚLIO CESAR MISTRO ${ }^{(6)}$; MARCUS VINICIUS SALOMON ${ }^{(6)}$
}

\begin{abstract}
RESUMO
O emprego da técnica de indução de mutação associada à hibridação tem contribuído para a obtenção de novos genótipos de trigo com características agronômicas desejáveis. Avaliaram-se 18 linhagens de trigo, sendo dez oriundas de seleção de plantas do híbrido Kauz "S"x IAC-24 que tiveram as sementes, em geração $F_{2}$, irradiadas (I) com raios gama e oito não irradiadas (NI), além das cultivares IAC-24 e IAC-289, em seis experimentos instalados no período 1997-99. Foram analisadas a produção de grãos, a resistência a doenças e outras características agronômicas. Em condições de laboratório, estudou-se a tolerância ao alumínio em soluções nutritivas, utilizando-se as cultivares BH-1146 (tolerante) e Anahuac (sensível), como controles. A linhagem L18-I destacou-se quanto à produção de grãos em condição de irrigação por aspersão e solo corrigido, nos três anos considerados. Em solo ácido e condição de sequeiro, L20-I, tolerante à toxicidade de $\mathrm{Al}^{3+}$, em soluções nutritivas, destacou-se quanto à produção de grãos, diferindo somente da IAC-289, a mais sensível à toxicidade de $\mathrm{Al}^{3+}$. IAC-289 e L9-NI destacaram-se na condição de sequeiro e solo corrigido, diferindo somente das linhagens L3-NI e L11-I. Na linhagem L11-I, observou-se porte mais baixo em todos os experimentos associado à resistência ao acamamento e à tolerância à toxicidade de $\mathrm{Al}^{3+}$. Todos os genótipos foram suscetíveis ao agente causal da mancha-dafolha. L9-NI tem potencial como fonte de genes em programas de melhoramento genético dada sua resistência à ferrugem-da-folha. Com exceção de Anahuac, IAC-289 e da L3-NI, todos os genótipos foram tolerantes à presença de $10 \mathrm{mg} \mathrm{L}^{-1}$ de $\mathrm{Al}^{3+}$ em soluções nutritivas.
\end{abstract}

Palavras-chave: linhagens de trigo, indução de mutação, produção de grãos, resistência às doenças, características agronômicas, tolerância à toxicidade de alumínio.

\section{ABSTRACT \\ EVALUATION OF WHEAT INBRED LINES ORIGINATED FROM HYBRIDIZATIONS WITH AND WITHOUT GAMMA IRRADIATION}

The mutation induction technique associated with hybridization has provided the development of new genotypes with desirable agronomic traits. Seeds of eighteen $\mathrm{F}_{2}$ wheat lines being ten originated by plant selections of the Kauz "S" $\mathrm{x}$ IAC-24 hybrid, were irradiated (I) with gamma rays and eight non

$\left({ }^{1}\right)$ Trabalho parcialmente financiado pela FAPESP. Apresentado no $1 .{ }^{\circ}$ Congresso Brasileiro de Melhoramento de Plantas, realizado em Goiânia, GO, em 2001. Recebido para publicação em 12 de abril e aceito em 23 de novembro de 2004.

$\left(^{2}\right)$ Instituto Agronômico (IAC), Centro de Análise e Pesquisa Tecnológica do Agronegócio de Grãos e Fibras, Caixa Postal 28, 13001-970 Campinas (SP).

$\left({ }^{3}\right)$ Centro de Energia Nuclear na Agricultura (CENA), Universidade de São Paulo (USP), Caixa Postal 96, $13400-970$ Piracicaba (SP).

$\left({ }^{4}\right)$ Unidade de Pesquisa do Desenvolvimento de Tatuí, Caixa Postal 33, 18270-000 Tatuí (SP).

$\left({ }^{5}\right)$ Pólo Regional de Desenvolvimento Tecnológico dos Agronegócios do Sudoeste Paulista, Caixa Postal 62, 18300-970 Capão Bonito (SP).

$\left({ }^{6}\right)$ Bolsista de Mestrado da FAPESP.

( ${ }^{7}$ ) Com bolsa de produtividade em pesquisa do CNPq. 
irradiated (NI) plus the check cultivars IAC-24 and IAC-289 were evaluated for grain yield, agronomic characteristics and disease resistance in six trials carried out at different locations, under sprinkler irrigation (limed soils) and dryland (limed and acid soils) conditions, during 1997-99. In laboratory conditions, the genotypes were evaluated for their toxicity tolerance in nutrient solutions using as controls the cultivars BH-1146 (tolerant) and Anahuac (sensitive). The line L18-I was superior for grain yield under limed soil and sprinkler irrigation conditions. Under dryland and acid soil, the line L20-I, tolerant to $\mathrm{Al}^{3+}$ toxicity in nutrient solutions, presented good grain yield differing only from IAC-289, the most sensitive to $\mathrm{Al}^{3+}$ toxicity. IAC-289 and line L9-NI had good performance under limed soil and dryland conditions. L11-I exhibited the shortest plants in all trials, to lodging resistance and tolerance to $\mathrm{Al}^{3+}$ toxicity. All genotypes were susceptible to leaf spot. L9-NI had good potential as source of resistance to leaf rust. Except to Anahuac, IAC-289 and line L3-NI, all genotypes were tolerant to the presence of 10 $\mathrm{mg} \mathrm{L}^{-1}$ of $\mathrm{Al}^{3+}$, in nutrient solutions.

Key words: wheat inbred lines, induced mutation, grain yield, disease resistance, agronomic characteristics, aluminum toxicity.

\section{INTRODUÇÃO}

A indução de mutação é considerada um método alternativo para aumentar a variabilidade genética no melhoramento de plantas. O emprego dessa técnica associada à hibridação, tem contribuído para a obtenção de novos genótipos de trigo com características desejáveis, visando corrigir algum defeito que em determinada cultivar possa ocorrer (SiguRbJORSSON, 1977).

O uso da radiação gama no programa de melhoramento genético de trigo do Instituto Agronômico (IAC) iniciou-se em 1978, com a obtenção de mutantes de porte semi-anão ou resistentes às ferrugens. Novos trabalhos coordenados pela Agência Internacional de Energia Atômica, Áustria, foram iniciados em 1985. Nessa época, sementes de algumas cultivares de destaque foram irradiadas visando à melhoria de algumas características agronômicas específicas, dentre elas a tolerância ao alumínio tóxico presente em solos ácidos (TuLMANN-Neto et al., 1995; CAMARGo et al., 1997).

Por meio da irradiação gama em sementes da cultivar Anahuac, sensível à toxicidade de $\mathrm{Al}^{3+}$, seguido de seleções nas gerações subseqüentes, foram obtidas 12 linhagens mutantes tolerantes. Essas linhagens e as cultivares tolerantes ao alumínio, 'IAC24 'e 'BH-1146', foram cruzadas com cultivares sensíveis. Em plântulas em geração $F_{2}$, obtidas desses cruzamentos, avaliadas em soluções nutritivas, contendo $2 \mathrm{mg} . \mathrm{L}^{-1}$ de $\mathrm{Al}^{3+}$, observou-se que a tolerância das linhagens mutantes era decorrente de um par de genes dominantes, e esses alelos expressavam a mesma tolerância das cultivares IAC-24 e BH-1146 (CAMARgo et al., 2000).

Outro aspecto do trabalho desenvolvido no IAC foi o uso da radiação gama em sementes de uma população $\mathrm{F}_{4}$ proveniente de cruzamento interespecífico entre a cultivar BH-1146 (Triticum aestivum L. / trigo para panificação) e a linhagem oriunda do híbrido 'Anhinga' " $\mathrm{S}$ " $\mathrm{x}$ 'Winged' "S" (Triticum durum L. / trigo para a indústria de massas). Linhagens de alto valor agronômico foram obtidas, estimulando o grupo a trabalhar com mais persistência nesse assunto (CAMARGO et al., 1995). Recentemente, o programa de melhoramento genético de trigo do IAC iniciou, em colaboração com o CENA/ USP, o uso de radiação gama em sementes híbridas para aumentar a freqüência de mutações e de recombinantes.

O objetivo deste trabalho foi avaliar o desempenho de linhagens de trigo originárias de hibridações com e sem irradiação gama nas sementes da geração $F_{2}$, em comparação com duas cultivarescontrole.

\section{MATERIAL E MÉTODOS}

Incluíram-se nos experimentos oito linhagens (3 a 10), provenientes de cruzamentos entre a linhagem Kauz "S", selecionada em experimento introduzido do Centro Internacional de Melhoramento de Milho e Trigo (CIMMYT)/ México, e a variedade nacional IAC-24, recomendada para cultivo no Estado de São Paulo, cujas sementes na geração $F_{2}$ não foram submetidas à irradiação gama (NI). Foram também incluídas 10 linhagens (11 a 20) originárias de cruzamentos entre os mesmos parentais anteriormente relacionados, cujas sementes na geração $\mathrm{F}_{2}$ foram irradiadas (I) com raios gama ( 27,5 krads) e as cultivares-controle 'IAC-24' (1) e 'IAC$289^{\prime}(2)$.

Empregou-se o delineamento estatístico de blocos ao acaso, com quatro repetições por local. Cada experimento constituiu-se de 80 parcelas, cada uma formada por seis linhas de $3 \mathrm{~m}$ de comprimento, espaçadas de 0,20 m. Deixou-se uma separação lateral 
de $0,60 \mathrm{~m}$ entre as parcelas, semeando-se 80 sementes viáveis por metro linear de sulco, com área de colheita de $3,6 \mathrm{~m}^{2}$.

Em 1997, realizaram-se dois experimentos, nos seguintes locais: Tatuí (latitude $23^{\circ} 20^{\prime} \mathrm{S}$, longitude $47^{\circ} 52^{\prime} \mathrm{W}$ e altitude $600 \mathrm{~m}$ ) e Capão Bonito (latitude $24^{\circ} 00^{\prime} \mathrm{S}$, longitude $48^{\circ} 22^{\prime} \mathrm{W}$ e altitude $702 \mathrm{~m}$ ). Em 1998 e 1999, foram instalados quatro experimentos nos seguintes locais: Tatuí e Tietê (latitude $23^{\circ} 07^{\prime} \mathrm{S}$, longitude $47^{\circ} 43^{\prime} \mathrm{W}$ e altitude $538 \mathrm{~m}$ ). O experimento de Capão Bonito desenvolveu-se em solo ácido sem correção com calcário e, portanto, com problemas de toxicidade de $\mathrm{Al}^{3+}$. Nos dois outros locais, o solo foi corrigido anteriormente com a prática da calagem. Empregou-se irrigação por aspersão nos experimentos instalados em Tatuí. Os demais foram semeados em condição de sequeiro.

Os genótipos foram comparados quanto à resistência à ferrugem-da-folha (Puccinia triticina) e mancha foliar (Bipolaris sorokiniana), procedendo-se a avaliação da severidade das doenças sob infecção natural.

A ferrugem-da-folha foi avaliada em cada parcela, pela observação das folhas superiores das plantas nos estádios 11.1 e 11.2 da escala de FeekesLarge, baseando-se em escala modificada de Cobb, conforme SchrAmm et al. (1974), que leva em conta a porcentagem de área infectada e o tipo de pústula, ou seja, a intensidade da doença e a reação da planta. Para mancha foliar, tomou-se como base para a avaliação uma escala de porcentagem de área foliar infectada, apresentada por Menta (1978).

Outras características fenológicas foram avaliadas de acordo com CAMARGO et al. (1995). Para determinar o ciclo das plantas, em dias, da emergência ao florescimento e da emergência à maturação, foram considerados apenas os dados obtidos nos experimentos de Capão Bonito (1997) e Tietê (1998 e 1999). Para avaliar o comprimento das espigas, do número de espiguetas por espiga, do número de grãos por espiga e por espigueta e da massa de cem grãos, foram colhidas dez espigas de cada parcela, apenas nos experimentos instalados em Tatuí (1997 e 1998).

Os dados das características avaliadas foram submetidos à análise de variância, utilizando-se o teste F, a $5 \%$, para detectar efeitos significativos de genótipos, repetições e possíveis interações. As médias das características avaliadas nos experimentos instalados em Tatuí foram utilizadas para estimar as correlações simples com a produção média de grãos dos 20 genótipos.

Avaliaram-se, em solução nutritiva e em condição de laboratório, de acordo com CAMARGO e
Oliveira (1981) e CAmargo et al. (1998), as plântulas dos 20 genótipos mais outras duas cultivares-controle: BH-1146 (tolerante) e Anahuac (sensível), a fim de avaliar a tolerância à toxicidade de alumínio, usandose as doses $0,2,4,6,8$ e $10 \mathrm{mg} . \mathrm{L}^{-1}$ de $\mathrm{Al}^{3+}$.

O delineamento experimental utilizado foi em blocos ao acaso, com duas repetições, dispostos em parcelas subdivididas: as parcelas, compostas de seis concentrações de alumínio e as subparcelas, de genótipos de trigo. $\mathrm{Na}$ análise dos dados considerouse a média do comprimento da raiz primária central das dez plântulas de cada genótipo, para cada repetição. Os genótipos com crescimento radicular foram considerados tolerantes; aqueles sem crescimento das raízes foram considerados sensíveis, depois de 72 horas em solução nutritiva completa sem alumínio, que se seguiu a 48 horas de crescimento nas soluções contendo seis diferentes concentrações de alumínio (CAMARGo, 1984 e Moore et al., 1976).

As correlações simples foram obtidas entre as produções médias de grãos dos 20 genótipos do experimento semeado em solo ácido de Capão Bonito e os crescimentos médios das raízes dos genótipos. Esse crescimento foi medido após 72 horas de crescimento na solução nutritiva, que se seguiu ao crescimento na solução-tratamento contendo 2, 4, 6, 8 e $10 \mathrm{mg} \mathrm{L}^{-1}$ de $\mathrm{Al}^{3+}$.

\section{RESULTADOS E DISCUSSÃO}

As análises da variância (individuais e conjuntas) e os testes de médias, para a variável produção média de grãos, estão apresentados na tabela 1. Os quadrados médios da análise da variância conjunta das produções de grãos dos genótipos avaliados nos três experimentos de Tatuí (1997-99), utilizando-se irrigação por aspersão e solo corrigido, mostraram-se significativos para anos, genótipos e para a interação genótipos $\mathrm{x}$ anos. $\mathrm{O}$ desdobramento dos efeitos de genótipos exibiram efeitos significativos para cultivares (testemunhas), linhagens e ao contraste cultivares (testemunhas) vs. linhagens. Desdobrando-se os efeitos de linhagens verificaramse efeitos significativos para linhagens irradiadas, linhagens não irradiadas e ao contraste entre elas. Considerando-se as médias do experimento instalado em Tatuí, em 1997 (Tabela 1), a linhagem L18-I, com produtividade média de grãos de $4.118 \mathrm{~kg} \mathrm{ha}^{-1}$, foi a mais produtiva, não diferindo, porém, somente das linhagens L6-NI, L15-I, L16-I, L17-I e L19-I, que tiveram produções médias de grãos variando entre 3.180 e $3.771 \mathrm{~kg} \mathrm{ha}^{-1}$ e das cultivares- controle IAC24 (média de $3.576 \mathrm{~kg} \mathrm{ha}^{-1}$ ) e IAC-289 (média de 3.694 $\left.\mathrm{kg} \mathrm{ha}{ }^{-1}\right)$. 
Tabela 1. Testes de médias e análises da variância individuais e conjuntas (locais) para a variável produção média de grãos, em $\mathrm{kg}^{-1}{ }^{-1}$, dos 20 genótipos de trigo avaliados nos Experimentos de Novas Linhagens Provenientes de Irradiação Gama, instalados em Tatuí, em 1997, 1998 e 1999; em Capão Bonito, em 1997; e em Tietê, em 1998 e 1999

\begin{tabular}{|c|c|c|c|c|c|c|c|c|c|c|c|c|c|}
\hline \multirow{4}{*}{$\begin{array}{l}\text { Genótipos } \\
1\end{array}$} & \multirow{2}{*}{\multicolumn{4}{|c|}{ Genealogia }} & \multicolumn{7}{|c|}{ Tatuí } & \multirow{2}{*}{$\begin{array}{c}\text { Capão Bonito } \\
1997\end{array}$} & \multirow{2}{*}{$\frac{\text { Tietê }}{\text { Média 1998/99 }}$} \\
\hline & & & & & \multicolumn{2}{|c|}{1997} & \multicolumn{2}{|c|}{1998} & \multicolumn{2}{|c|}{1999} & \multirow{2}{*}{ Média } & & \\
\hline & & & & & & & & & & $\mathrm{kg}$ & & & \\
\hline & IAC - 24 & & & & 3.576 & $a-c$ & 3.785 & $\mathrm{a}$ & 4.736 & $a-c$ & 4.032 & $1.726 \mathrm{ab}$ & $3.205 \mathrm{ab}$ \\
\hline 2 & IAC - 289 & & & & 3.694 & $a-c$ & 2.792 & $d-f$ & 3.910 & $b-h$ & 3.465 & $795 \mathrm{~b}$ & 3.830 a \\
\hline 3 & Kauz"S" & $x$ & IAC -24 & NI & 2.368 & e & 2.424 & $\mathrm{f}$ & 2.910 & $\mathrm{~h}$ & 2.567 & $1.240 \mathrm{ab}$ & $2.608 \mathrm{~b}$ \\
\hline 4 & Kauz"S" & $x$ & IAC -24 & NI & 2.972 & b-e & 3.181 & $a-f$ & 4.236 & $a-f$ & 3.463 & $1.347 \mathrm{ab}$ & $3.424 \mathrm{ab}$ \\
\hline 5 & Kauz"S" & $x$ & IAC - -24 & NI & 2.944 & b-e & 2.930 & $b-f$ & 3.354 & $\mathrm{f}-\mathrm{h}$ & 3.076 & $1.427 \mathrm{ab}$ & $2.906 \mathrm{ab}$ \\
\hline 6 & Kauz"S" & $x$ & IAC -24 & NI & 3.507 & $a-d$ & 3.569 & $a-d$ & 4.833 & $\mathrm{ab}$ & 3.970 & $1.462 \mathrm{ab}$ & $3.594 \mathrm{ab}$ \\
\hline 7 & Kauz"S" & $x$ & IAC - -24 & NI & 2.854 & b-e & 3.049 & $a-f$ & 4.104 & $a-g$ & 3.336 & $1.389 \mathrm{ab}$ & $3.188 \mathrm{ab}$ \\
\hline 8 & Kauz"S" & $x$ & IAC -24 & NI & 3.104 & b-e & 3.326 & a-e & 3.583 & e-h & 3.338 & $1.424 \mathrm{ab}$ & $3.201 \mathrm{ab}$ \\
\hline 9 & Kauz"S" & $x$ & IAC - -24 & NI & 3.063 & b-e & 3.056 & $a-f$ & 4.312 & $a-f$ & 3.477 & $1.031 \mathrm{ab}$ & $3.722 \mathrm{a}$ \\
\hline 10 & Kauz"S" & $x$ & IAC -24 & NI & 2.917 & b-e & 3.035 & $a-f$ & 3.931 & $a-h$ & 3.294 & $1.083 \mathrm{ab}$ & $3.389 \mathrm{ab}$ \\
\hline 11 & Kauz"S" & $x$ & IAC - -24 & I & 2.549 & de & 2.507 & ef & 3.521 & $e-h$ & 2.859 & $1.202 \mathrm{ab}$ & $2.604 \mathrm{~b}$ \\
\hline 12 & Kauz"S" & $x$ & IAC -24 & I & 2.729 & c-e & 2.875 & $c-f$ & 3.597 & $\mathrm{~d}-\mathrm{h}$ & 3.067 & $1.594 \mathrm{ab}$ & $2.917 \mathrm{ab}$ \\
\hline 13 & Kauz"S" & $x$ & IAC -24 & I & 2.965 & b-e & 3.153 & $a-f$ & 3.514 & $e-h$ & 3.211 & $1.424 \mathrm{ab}$ & $3.198 \mathrm{ab}$ \\
\hline 14 & Kauz"S" & $\mathrm{x}$ & IAC -24 & I & 3.021 & b-e & 3.257 & $a-f$ & 3.646 & $c-h$ & 3.308 & $1.483 \mathrm{ab}$ & $3.563 \mathrm{ab}$ \\
\hline 15 & Kauz"S" & $x$ & IAC -24 & I & 3.375 & $a-d$ & 3.743 & $\mathrm{ab}$ & 3.049 & gh & 3.389 & $1.431 \mathrm{ab}$ & $3.319 \mathrm{ab}$ \\
\hline 16 & Kauz"S" & $x$ & IAC -24 & I & 3.771 & $\mathrm{ab}$ & 3.333 & a-e & 4.701 & $a-d$ & 3.935 & $1.320 \mathrm{ab}$ & $3.257 \mathrm{ab}$ \\
\hline 17 & Kauz"S" & $x$ & IAC -24 & I & 3.438 & $a-d$ & 3.632 & $a-c$ & 3.889 & $b-h$ & 3.653 & $1.125 \mathrm{ab}$ & $3.476 \mathrm{ab}$ \\
\hline 18 & Kauz"S" & $x$ & IAC -24 & I & 4.118 & $\mathrm{a}$ & 3.771 & $\mathrm{a}$ & 5.028 & a & 4.305 & $1.771 \mathrm{ab}$ & $3.416 \mathrm{ab}$ \\
\hline 19 & Kauz"S" & $x$ & IAC -24 & I & 3.180 & a-e & 3.417 & $a-d$ & 4.319 & $a-f$ & 3.639 & $1.760 \mathrm{ab}$ & $3.049 \mathrm{ab}$ \\
\hline 20 & Kauz"S" & $x$ & IAC -24 & $\mathrm{I}$ & 3.035 & b-e & 3.722 & $\mathrm{ab}$ & 4.549 & a-e & 3.768 & $1.820 \mathrm{a}$ & $2.861 \mathrm{ab}$ \\
\hline F (Genótipos) & - & - & - & - & 5,1 & $3^{*}$ & & $44^{*}$ & & $08^{*}$ & $5,60^{*}$ & $2,02^{*}$ & $3,47^{*}$ \\
\hline F (Anos) & - & - & - & - & - & & - & & - & & $45,28^{*}$ & - & $3,07^{*}$ \\
\hline$F(G \times A)$ & - & - & - & - & - & & - & & - & & $2,41^{*}$ & - & 1,13 \\
\hline d.m.s. (Tukey 5\%) & - & - & - & - & 995 & & 840 & & & 1106 & 947 & 986 & 1042 \\
\hline C.V. $(\%)$ & - & - & - & - & $12,($ & & 9,9 & 91 & 10, & & 11,36 & 26,97 & 14,92 \\
\hline
\end{tabular}

* Significativo a 5\%; NI= não irradiado e I= irradiado 
A linhagem L18-I (média de $3.771 \mathrm{~kg} \mathrm{ha}^{-1}$ ) destacou-se quanto à produção de grãos em Tatuí, em 1998, somente diferindo de 'IAC-289' (média de 2.792 $\mathrm{kg} \mathrm{ha}^{-1}$ ) e das linhagens L3-NI (média de $2.424 \mathrm{~kg} \mathrm{ha}$ ${ }^{1}$ ), L5-NI (média de $2.930 \mathrm{~kg} \mathrm{ha}^{-1}$ ), L11-I (média de $2.507 \mathrm{~kg} \mathrm{ha}^{-1}$ ) e L12-I (média de $2.875 \mathrm{~kg} \mathrm{ha}^{-1}$ ). No experimento instalado em 1999, novamente com a linhagem L18-I (média de $5.028 \mathrm{~kg} \mathrm{ha}^{-1}$ ) constatou-se a maior produção de grãos, apenas não diferindo de 'IAC-24' (média de $4.736 \mathrm{~kg} \mathrm{ha}^{-1}$ ) e das linhagens L4NI, L6-NI, L7-NI, L9-NI, L10-NI, L16-I, L19-I e L20-I cujas produções médias de grãos variaram entre 4.104 e $4.833 \mathrm{~kg} \mathrm{ha}^{-1}$.

Considerando-se as médias de produção de grãos do experimento instalado em Capão Bonito, em 1997 (Tabela 1), em condição de sequeiro, solo ácido e com problemas de toxicidade de $\mathrm{Al}^{3+}$, a linhagem L20-I (média de $1.820 \mathrm{~kg} \mathrm{ha}^{-1}$ ) foi a mais produtiva, diferindo apenas da 'IAC-289' (média de $795 \mathrm{~kg} \mathrm{ha}^{-1}$ ), sensível à toxicidade de $\mathrm{Al}^{3+}$.

Os quadrados médios da análise da variância conjunta das produções de grãos dos genótipos avaliados nos dois experimentos de Tietê (1998-99), em condição de sequeiro e solo corrigido, foram significativos para genótipos e para anos e não significativos para a interação genótipos $\mathrm{x}$ anos. $\mathrm{O}$ desdobramento dos efeitos de genótipos exibiram efeitos significativos para cultivares (testemunhas), para linhagens e para o contraste cultivares (testemunhas) vs. linhagens. Desdobrando-se os efeitos de linhagens verificaram-se efeitos significativos para linhagens irradiadas, para linhagens não irradiadas e não significativos para o contraste entre linhagens irradiadas e linhagens não irradiadas. As produções médias de grãos dos genótipos avaliados em Tietê (1998-99) são apresentadas na tabela 1, conforme citado anteriormente. Considerando-se em conjunto esses dois experimentos, verificou-se que a cultivar IAC-289 (média de $3.830 \mathrm{~kg} \mathrm{ha}^{-1}$ ) e a linhagem L9-NI (média de $3.722 \mathrm{~kg} \mathrm{ha}^{-1}$ ) foram as mais produtivas, diferindo somente das linhagens L3-NI (média de $2.608 \mathrm{~kg} \mathrm{ha}^{-1}$ ) e L11-I (média de $2.604 \mathrm{~kg} \mathrm{ha}^{-1}$ ).

Pelos resultados obtidos no período de 19971999, nos três locais, constatou-se que entre as linhagens mais produtivas estavam as oriundas de hibridações seguidas ou não de irradiação gama.

Os quadrados médios da análise da variância conjunta das alturas das plantas dos genótipos, avaliados nos três experimentos de Tatuí (1997-1999), mostraram-se significativos para genótipos e anos, e não significativos para a interação genótipos $x$ anos. Considerando-se os dois experimentos de Tietê (19981999) os quadrados médios da análise da variância conjunta das alturas das plantas mostrou efeitos significativos apenas para genótipos (Tabela 2).
Considerando-se as médias dos experimentos de Tatuí, Capão Bonito e Tietê (Tabela 2), verificouse na linhagem L11-I as plantas mais baixas $(54,48 \mathrm{e}$ $51 \mathrm{~cm}$ respectivamente). Em Tatuí, essa linhagem somente não diferiu de L3-NI $(56 \mathrm{~cm})$; em Capão Bonito não diferiu de L3-NI, L4-NI, L5-NI, L7-NI, L12I, L14-I e L19-I, e em Tietê, apenas não diferiu de L3-NI, L7-NI e L12-I.

A linhagem L18-I destacou-se dentre as que apresentaram as plantas mais altas, considerando as médias dos experimentos instalados em cada um dos três locais avaliados. A L18-I não diferiu em Tatuí de 'IAC-24' e 'IAC-289' e das linhagens L6-NI, L9-NI, L10-NI, L16-I e L20-I. Em Capão Bonito, de 'IAC-24' e das linhagens L10-NI, L13-I, L16-I e L20-I, e em Tietê de 'IAC-24 e 'IAC-289' e das linhagens L6-NI, L9-NI, L13-I, L16-I, L17-I e L20-I.

Independentemente da origem do genótipo avaliado (hibridações seguidas ou não de irradiação gama), foram obtidas linhagens com plantas altas ou baixas.

As porcentagens médias de acamamento dos genótipos estudados nos experimentos de Tatuí, encontram-se na tabela 2. Todos os genótipos avaliados podem ser considerados de porte semi-anão, com altura de planta variando de $54 \mathrm{a} 86 \mathrm{~cm}$. Devido a este fato, verificou-se porcentagem máxima de acamamento de $13 \%$. Com as linhagens L9-NI e L18I, com porte de 82 e $86 \mathrm{~cm}$ respectivamente, ocorreram as maiores porcentagens de acamamento (13\%). Com a linhagem L11-I, de plantas mais baixas $(54 \mathrm{~cm})$, não houve ocorrência de plantas acamadas. Não ocorreu acamamento também nas linhagens L6-NI e L15-I, apesar de terem plantas altas, evidenciando que há outro mecanismo genético de resistência ao acamamento. Apesar das exceções já consideradas, as plantas mais altas tendem a ter maior porcentagem de acamamento em relação às de menor porte.

As análises da variância (individuais e conjuntas) e os testes de médias, para as variáveis ciclos da emergência ao florescimento e da emergência à maturação estão apresentados na tabela 3. Os quadrados médios da análise da variância conjunta dos ciclos da emergência ao florescimento e da emergência à maturação dos genótipos avaliados nos experimentos de Capão Bonito (1997) e de Tietê (19981999) foram significativos para experimentos, genótipos e para a interação genótipos x experimentos.

Considerando-se as médias individuais dos ciclos da emergência ao florescimento dos três experimentos, observaram na linhagem L20-I plantas mais tardias para florescer, isto é, 71, 77 e 68 dias. A linhagem L9-NI foi a mais precoce para florescer, ou seja, um ciclo da emergência ao florescimento de 49 dias em Capão Bonito (1997) e de 56 e 53 dias nos experimentos de Tietê (1998-1999). 
Tabela 2. Testes de médias e análises da variância individuais e conjuntas (locais) para a variável altura da planta, em cm, e acamamento, em porcentagem, dos 20 genótipos de trigo avaliados nos Experimentos de Novas Linhagens Provenientes de Irradiação Gama, instalados em Tatuí, em 1997, 1998 e 1999, em Capão Bonito, em 1997 e em Tietê, em 1998 e 1999

\begin{tabular}{|c|c|c|c|c|c|c|c|c|}
\hline \multirow{2}{*}{ Genótipos } & & \multirow{2}{*}{\multicolumn{3}{|c|}{ Genealogia }} & \multicolumn{3}{|c|}{ Altura da planta } & \multirow{2}{*}{$\begin{array}{c}\text { Acamamento } \\
\text { Tatuí } 1997 / 99 \\
\%\end{array}$} \\
\hline & & & & & Tatuí 1997/99 & Capão Bonito 1997 & Tietê 1998/99 & \\
\hline 1 & IAC - 24 & - & - & - & $87 \mathrm{a}$ & 64 a-c & $77 \mathrm{ab}$ & 7 \\
\hline 2 & IAC - 289 & - & - & - & $85 \mathrm{ab}$ & $58 \quad b-e$ & $76 \mathrm{ab}$ & 7 \\
\hline 3 & Kauz"S" & $x$ & IAC -24 & NI & $56 \mathrm{kl}$ & $48 \mathrm{f}$ & $53 \mathrm{gh}$ & 0 \\
\hline 4 & Kauz"S" & $x$ & IAC -24 & $\mathrm{NI}$ & $69 \mathrm{gh}$ & $55 \quad c-f$ & 61 ef & 3 \\
\hline 5 & Kauz"S" & $x$ & IAC -24 & NI & $63 \mathrm{ij}$ & $56 c-f$ & $59 \mathrm{fg}$ & 7 \\
\hline 6 & Kauz"S" & $x$ & IAC -24 & NI & $83 \mathrm{ab}$ & 59 b-e & 72 a-c & 0 \\
\hline 7 & Kauz"S" & $x$ & IAC -24 & NI & $66 \mathrm{hi}$ & $53 \mathrm{~d}-\mathrm{f}$ & $58 \mathrm{f}-\mathrm{h}$ & 0 \\
\hline 8 & Kauz"S" & $x$ & IAC -24 & $\mathrm{NI}$ & $71 \mathrm{f}-\mathrm{h}$ & 58 b-e & $63 \mathrm{~d}-\mathrm{f}$ & 7 \\
\hline 9 & Kauz"S" & $x$ & IAC -24 & $\mathrm{NI}$ & 82 a-c & 58 b-e & 71 a-c & 13 \\
\hline 10 & Kauz"S" & $x$ & IAC -24 & $\mathrm{NI}$ & 82 a-c & 61 a-d & $70 \quad b-d$ & 7 \\
\hline 11 & Kauz"S" & $\mathrm{x}$ & IAC -24 & I & 541 & $48 \mathrm{f}$ & $51 \mathrm{~h}$ & 0 \\
\hline 12 & Kauz"S" & $x$ & IAC -24 & I & $60 \mathrm{jk}$ & 51 ef & $52 \mathrm{gh}$ & 0 \\
\hline 13 & Kauz"S" & $x$ & IAC -24 & I & 77 c-e & 61 a-d & 72 a-c & 3 \\
\hline 14 & Kauz"S" & $x$ & IAC -24 & I & $62 \mathrm{ij}$ & $54 \mathrm{~d}-\mathrm{f}$ & $59 \mathrm{fg}$ & 0 \\
\hline 15 & Kauz"S" & $\mathrm{x}$ & IAC -24 & I & 74 e-g & 58 b-e & 70 b-d & 0 \\
\hline 16 & Kauz"S" & $\mathrm{x}$ & IAC -24 & I & $85 \mathrm{ab}$ & $64 a-c$ & $77 \mathrm{ab}$ & 3 \\
\hline 17 & Kauz"S" & $\mathrm{x}$ & IAC -24 & I & $80 \mathrm{~b}-\mathrm{d}$ & 58 b-e & 72 a-c & 3 \\
\hline 18 & Kauz"S" & $\mathrm{x}$ & IAC -24 & I & 86 a & 69 a & 78 a & 13 \\
\hline 19 & Kauz"S" & $\mathrm{x}$ & IAC -24 & I & $76 \mathrm{~d}-\mathrm{f}$ & 56 c-f & 68 c-e & 3 \\
\hline 20 & Kauz"S" & $\mathrm{x}$ & IAC -24 & I & 82 a-c & $66 \mathrm{ab}$ & $76 \mathrm{ab}$ & 7 \\
\hline F (Genótipos) & - & - & - & - & $81,21^{*}$ & $8,70 *$ & $37,89^{*}$ & - \\
\hline F (Anos) & - & - & - & - & $175,80^{*}$ & - & 0,19 & - \\
\hline$F(G \times A)$ & - & - & - & - & 1,36 & - & 0,87 & - \\
\hline d.m.s. (Tukey 5\%) & - & - & - & - & 6 & 10 & 8 & - \\
\hline -C.V. (\%) & - & - & - & - & 4,76 & 6,61 & 6,69 & - \\
\hline
\end{tabular}

*Significativo a $5 \%$; NI= não irradiado e $\mathrm{I}=$ irradiado. 
Tabela 3. Testes de médias e análises da variância individuais e conjuntas (locais) para as variáveis ciclo da emergência ao florescimento e da emergência à maturação dos 20 genótipos de trigo avaliados nos Experimentos de Novas Linhagens Provenientes de Irradiação Gama, instalados em Capão Bonito, em 1997 e em Tietê, em 1998 e 1999

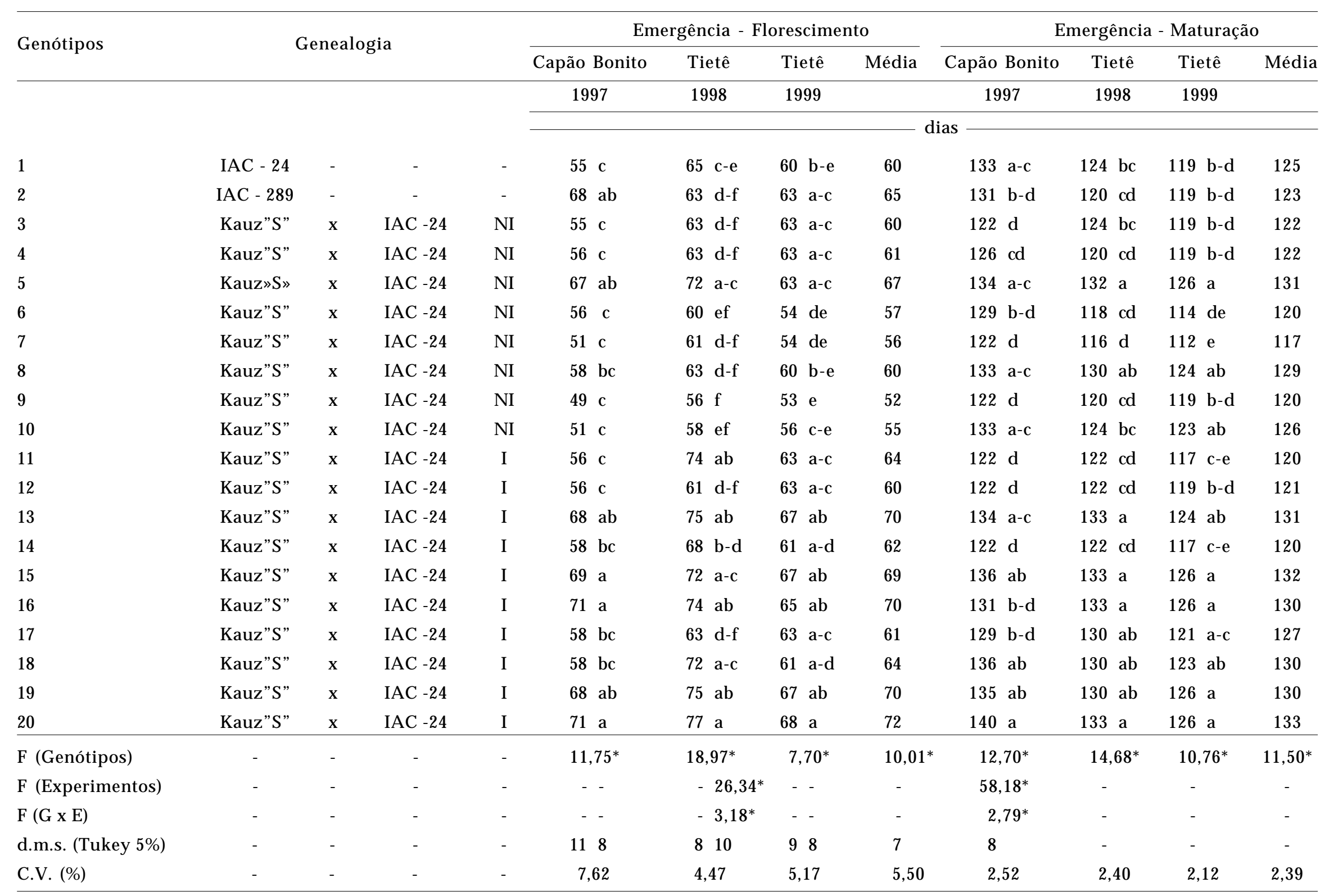


Considerando-se as médias individuais dos ciclos da emergência à maturação dos experimentos de Capão Bonito (1997) e de Tietê (1998-1999), na tabela 3, verifica-se que a linhagem L20-I tem um ciclo de, respectivamente,140, 133 e 126 dias, sendo a mais tardia entre os genótipos estudados. A linhagem L7$\mathrm{NI}$, a mais precoce para maturar, levou, nas mesmas condições, 122, 116 e 112 dias respectivamente.

$\mathrm{Na}$ tabela 4, são apresentados os dados médios de porcentagem de ferrugem-da-folha dos 20 genótipos de trigo avaliados nos experimentos instalados em Tatuí e Tietê. Houve baixa incidência da doença nos cinco experimentos considerados. $\mathrm{O}$ genótipo 9 foi o mais resistente ao agente causal dessa doença, com grau médio de infecção entre 0 e tS (Tabela 4). Os genótipos 3-NI, 5-NI, 8-NI, 10-NI, 15-I, 19-I e 20-I também foram considerados como tolerantes pelos baixos índices de ferrugem, isto é, um grau de infecção máximo entre 3 e $5 \mathrm{~S}$, em pelo menos um experimento. Pela resistência apresentada (baixa severidade da doença), em todos os experimentos considerados, sugere-se que o genótipo 9 possa servir como fonte de resistência em programa de melhoramento visando à resistência à ferrugem-dafolha do trigo.

Os graus médios de infecção de mancha-dafolha dos 20 genótipos avaliados nos experimentos instalados em Tatuí e Tietê são apresentados na tabela 5. Não foi possível diferenciar os genótipos (linhagens), quanto à resistência a essa doença, apesar de a L6-NI ser moderadamente resistente quando se considerou a média dos graus de infecção dos experimentos de Tatuí e de Tietê. Todos os genótipos foram suscetíveis, em pelo menos um experimento, não permitindo estabelecer diferenças de níveis de resistência entre eles. Em outros trabalhos, já foi confirmada a dificuldade de encontrar genótipos com resistência a Bipolaris sorokiniana (CAMARGO et al., 1994; 1995; 2001).

As análises da variância (individuais e conjuntas) e os testes de médias, para as variáveis comprimento da espiga, número de espiguetas por espiga, número de grãos por espiga e por espigueta, e massa de cem grãos - estão apresentados na tabela 6. Os quadrados médios da análise da variância conjunta dessas características dos genótipos avaliados nos dois experimentos de Tatuí (1997-1998) foram significativos para anos e genótipos. A interação genótipos $\mathrm{x}$ anos somente foi significativa para número de grãos por espiga e para massa de cem grãos.

As linhagens L4-NI e L8-NI, de espigas mais compridas, não diferiram, apenas de L3-NI, L5-NI e L20-I, quando se considerou a média do comprimento das espigas dos dois experimentos de Tatuí (19971998). Não se observaram, pelo teste Tukey, diferenças significativas entre os genótipos em relação ao número de espiguetas por espiga (Tabela 6). A cultivar IAC289 e a linhagem L13-I, com maior número de grãos por espiga no experimento de Tatuí (1997), diferiram somente de 'IAC-24' e das linhagens L5-NI, L9-NI, L10-NI e L11-I, com menor número. No experimento de Tatuí (1998), nas linhagens L13-I, L15-I, L17-I e L20-I, observaram maior número de grãos por espiga, diferindo apenas de 'IAC-24' e das linhagens L7-NI, L9-NI, L10-NI, L11-I e L16-I.

Por apresentar ao mesmo tempo, maior número de grãos por espiga e por espigueta, notou-se na linhagem L13-I potencial para ser empregada como fonte genética dessas características no programa de cruzamentos do Instituto Agronômico. Destacaram-se, também, pelo grande número de grãos por espigueta (grande fertilidade da espiga) as linhagens L6-NI e NL17-I, além da cultivar IAC-289, diferindo, porém, apenas de L11-I (Tabela 6).

As linhagens L18-I e L20-I possuem os grãos mais pesados no experimento de Tatuí (1997), não diferindo apenas das cultivares IAC-24 e IAC-289 e das linhagens L9-NI, L11-I e L16-I (Tabela 6). As linhagens L16-I e L18-I obtiveram os grãos mais pesados no experimento de Tatuí (1998), não diferindo apenas das duas cultivares e das linhagens L4-NI, L6NI, L7-NI, L9-NI, L17-I e L20-I.

A linhagem L18-I, também de grande potencial produtivo, portanto, representa um germoplasma de grande interesse aos programas de melhoramento de trigo, quando a característica grãos de maior peso for desejada. A massa de cem grãos foi a única característica em correlação simples significativa com a produção de grãos $(0,75)$, considerando os experimentos instalados em Tatuí, em condição de irrigação por aspersão (dados não apresentados). Esses resultados concordam com os obtidos por Camargo et al. (2003) e Mistro e Camargo (2002) os quais também concluíram que houve tendência de quanto maior a massa dos grãos, mais produtivas seriam as plantas.

Pela tabela 7, observa-se o comprimento médio das raízes dos 20 genótipos de trigo avaliados, além das cultivares-controle BH-1146 (tolerante) e Anahuac (sensível), após 72 horas de crescimento em solução normal (sem alumínio), que se seguiu ao crescimento em solução-tratamento, contendo seis diferentes concentrações de alumínio (média de duas repetições). Verificou-se a diminuição do crescimento das raízes primárias centrais de todos os genótipos, à medida que aumentaram as concentrações de alumínio. 
Tabela 4. Graus médios de infecção de ferrugem-da-folha ${ }^{(1)}$ dos 20 genótipos de trigo avaliados nos Experimentos de Novas Linhagens Provenientes de Irradiação Gama, instalados em Tatuí, em 1997, 1998 e 1999 e em Tietê, em 1998 e 1999

\begin{tabular}{|c|c|c|c|c|c|c|c|c|c|c|c|}
\hline \multirow{3}{*}{$\begin{array}{l}\text { Genótipos } \\
1\end{array}$} & \multirow{2}{*}{\multicolumn{4}{|c|}{ Genealogia }} & \multicolumn{4}{|c|}{ Tatuí } & \multicolumn{3}{|c|}{ Tietê } \\
\hline & & & & & \multirow{2}{*}{$\begin{array}{c}1997 \\
3 S\end{array}$} & \multirow{2}{*}{$\begin{array}{c}1998 \\
10 S\end{array}$} & \multirow{2}{*}{$\begin{array}{c}1999 \\
5 S\end{array}$} & \multirow{2}{*}{$\frac{\text { Média }}{6 \mathrm{~S}}$} & \multirow{2}{*}{$\begin{array}{c}1998 \\
0\end{array}$} & \multirow{2}{*}{$\begin{array}{c}1999 \\
0\end{array}$} & \multirow{2}{*}{$\frac{\text { Média }}{0}$} \\
\hline & IAC - 24 & - & - & - & & & & & & & \\
\hline 2 & IAC - 289 & - & - & - & $3 S$ & $5 S$ & $10 S$ & $6 S$ & $\mathrm{tS}$ & $10 \mathrm{~S}$ & $6 S$ \\
\hline 3 & Kauz"S" & $x$ & IAC -24 & NI & 0 & $5 S$ & $\mathrm{tS}$ & $2 S$ & 0 & 0 & 0 \\
\hline 4 & Kauz"S" & $x$ & IAC -24 & NI & $3 S$ & $10 S$ & $5 S$ & $6 S$ & 0 & $10 \mathrm{~S}$ & $5 S$ \\
\hline 5 & Kauz»S» & $x$ & IAC -24 & NI & 0 & $5 S$ & $5 S$ & $3 S$ & 0 & $\mathrm{tS}$ & $\mathrm{tS}$ \\
\hline 6 & Kauz»S» & $x$ & IAC -24 & NI & $6 S$ & $5 S$ & $5 S$ & $5 S$ & 0 & 0 & 0 \\
\hline 7 & Kauz»S» & $x$ & IAC -24 & NI & $13 S$ & $\mathrm{tS}$ & $20 S$ & $11 S$ & 0 & 0 & 0 \\
\hline 8 & Kauz»S» & $x$ & IAC -24 & NI & $\mathrm{tS}$ & $5 S$ & $5 S$ & $3 S$ & 0 & $5 S$ & $3 S$ \\
\hline 9 & Kauz"S" & $x$ & IAC -24 & NI & 0 & $\mathrm{tS}$ & $\mathrm{tS}$ & $\mathrm{tS}$ & 0 & 0 & 0 \\
\hline 10 & Kauz"S" & $x$ & IAC -24 & $\mathrm{NI}$ & $5 S$ & $\mathrm{tS}$ & $5 S$ & $3 S$ & tS & $5 S$ & $3 S$ \\
\hline 11 & Kauz"S" & $x$ & IAC -24 & I & $8 \mathrm{~S}$ & 0 & $5 S$ & $4 S$ & 0 & $10 \mathrm{~S}$ & $5 S$ \\
\hline 12 & Kauz"S" & $x$ & IAC -24 & I & $3 S$ & $\mathrm{tS}$ & $20 S$ & $8 S$ & 0 & $5 S$ & $3 S$ \\
\hline 13 & Kauz"S" & $x$ & IAC -24 & I & $10 \mathrm{~S}$ & $5 S$ & $10 S$ & $8 \mathrm{~S}$ & 0 & $10 \mathrm{~S}$ & $5 S$ \\
\hline 14 & Kauz"S" & $x$ & IAC -24 & I & $16 S$ & 0 & $10 S$ & $9 \mathrm{~S}$ & 0 & 0 & 0 \\
\hline 15 & Kauz"S" & $x$ & IAC -24 & I & $3 S$ & 0 & $5 S$ & $3 S$ & 0 & $\mathrm{tS}$ & tS \\
\hline 16 & Kauz"S" & $x$ & IAC -24 & I & $8 S$ & $5 S$ & $10 S$ & $8 S$ & 0 & $5 S$ & $3 S$ \\
\hline 17 & Kauz"S" & $x$ & IAC -24 & I & $10 S$ & $5 S$ & $10 \mathrm{~S}$ & $8 S$ & 0 & $10 \mathrm{~S}$ & $5 S$ \\
\hline 18 & Kauz"S" & $x$ & IAC -24 & I & $5 S$ & $10 S$ & $10 S$ & $8 S$ & 0 & $10 \mathrm{~S}$ & $5 S$ \\
\hline 19 & Kauz"S" & $x$ & IAC -24 & I & $3 S$ & $\mathrm{tS}$ & $\mathrm{tS}$ & $1 S$ & 0 & $\mathrm{tS}$ & $\mathrm{tS}$ \\
\hline 20 & Kauz"S" & $x$ & IAC -24 & I & $5 S$ & tS & $\mathrm{tS}$ & $2 S$ & 0 & $5 S$ & $3 S$ \\
\hline
\end{tabular}

$\left({ }^{1}\right) t=$ traço (apenas algumas pústulas); $\mathrm{S}=$ reação de suscetibilidade. Avaliação de ferrugem-da-folha foi feita segundo ScHRAMM et. al., 1974. NI= não irradiado e I= irradiado. 
Tabela 5. Graus médios de infecção de mancha-da-folha ${ }^{(1)}$ dos 20 genótipos de trigo avaliados nos Experimentos de Novas Linhagens Provenientes de Irradiação Gama, instalados em Tatuí, em1997, 1998 e 1999 e em Tietê, em 1998 e 1999

\begin{tabular}{|c|c|c|c|c|c|c|c|c|c|c|c|}
\hline \multirow{3}{*}{$\begin{array}{l}\text { Genótipos } \\
1\end{array}$} & \multirow{2}{*}{\multicolumn{4}{|c|}{ Genealogia }} & \multicolumn{4}{|c|}{ Tatuí } & \multicolumn{3}{|c|}{ Tietê } \\
\hline & & & & & \multirow{2}{*}{$\frac{1997}{15}$} & \multirow{2}{*}{$\frac{1998}{40}$} & \multirow{2}{*}{$\frac{1999}{30}$} & \multirow{2}{*}{$\frac{\text { Média }}{28}$} & \multirow{2}{*}{$\frac{1998}{10}$} & \multirow{2}{*}{$\frac{1999}{20}$} & \multirow{2}{*}{$\frac{\text { Média }}{15}$} \\
\hline & IAC - 24 & - & - & - & & & & & & & \\
\hline 2 & IAC - 289 & - & - & - & 15 & 30 & 30 & 25 & 40 & 20 & 30 \\
\hline 3 & Kauz"S" & $x$ & IAC -24 & NI & 40 & 50 & 40 & 43 & 40 & 30 & 35 \\
\hline 4 & Kauz»S» & $x$ & IAC -24 & NI & 25 & 50 & 20 & 32 & 30 & 20 & 25 \\
\hline 5 & Kauz"S" & $x$ & IAC -24 & NI & 20 & 50 & 20 & 30 & 10 & 40 & 25 \\
\hline 6 & Kauz»S» & $x$ & IAC -24 & NI & 20 & 30 & 20 & 23 & 20 & 10 & 15 \\
\hline 7 & Kauz"S" & $x$ & IAC -24 & $\mathrm{NI}$ & 30 & 50 & 40 & 40 & 20 & 40 & 30 \\
\hline 8 & Kauz»S» & $x$ & IAC -24 & NI & 25 & 40 & 20 & 28 & 20 & 20 & 20 \\
\hline 9 & Kauz"S" & $x$ & IAC -24 & $\mathrm{NI}$ & 20 & 50 & 20 & 30 & 10 & 10 & 10 \\
\hline 10 & Kauz»S» & $x$ & IAC -24 & NI & 20 & 40 & 20 & 27 & 30 & 20 & 25 \\
\hline 11 & Kauz"S" & $x$ & IAC -24 & I & 30 & 40 & 40 & 37 & 60 & 20 & 40 \\
\hline 12 & Kauz"S" & $x$ & IAC -24 & I & 35 & 40 & 40 & 38 & 20 & 40 & 30 \\
\hline 13 & Kauz"S" & $x$ & IAC -24 & I & 20 & 40 & 20 & 27 & 20 & 30 & 25 \\
\hline 14 & Kauz"S" & $x$ & IAC -24 & I & 25 & 50 & 40 & 38 & 30 & 40 & 35 \\
\hline 15 & Kauz"S" & $x$ & IAC -24 & I & 25 & 40 & 20 & 28 & 10 & 30 & 20 \\
\hline 16 & Kauz"S" & $x$ & IAC -24 & I & 25 & 30 & 30 & 28 & 10 & 20 & 15 \\
\hline 17 & Kauz"S" & $x$ & IAC - 24 & I & 25 & 40 & 30 & 32 & 20 & 20 & 20 \\
\hline 18 & Kauz"S" & $x$ & IAC -24 & I & 20 & 40 & 40 & 33 & 20 & 20 & 20 \\
\hline 19 & Kauz"S" & $x$ & IAC -24 & I & 30 & 40 & 30 & 33 & 30 & 20 & 25 \\
\hline 20 & Kauz"S" & $x$ & IAC -24 & I & 30 & 40 & 20 & 30 & 30 & 20 & 25 \\
\hline
\end{tabular}

$\left({ }^{1}\right)$ Avaliação de mancha-da-folha segundo Mehta (1978): $0=$ imune; $1 \%$ a $5 \%$ de área infectada $=$ resistente; $6 \%$ a $25 \%=$ moderadamente resistente; $26 \%$ a $50 \%=$ suscetível, e $5 \% 1$ a $99 \%$ = altamente suscetível; NI= não irradiado e I= irradiado. 
Tabela 6. Testes de médias e análises da variância conjuntas para as variáveis comprimento das espigas (C.E.), número de espiguetas por espiga, número de grãos por espiga e por espigueta e massa de cem grãos dos 20 genótipos de trigo avaliados nos Experimentos de Novas Linhagens Provenientes de Irradiação Gama, instalados em Tatuí, no período de 1997-98

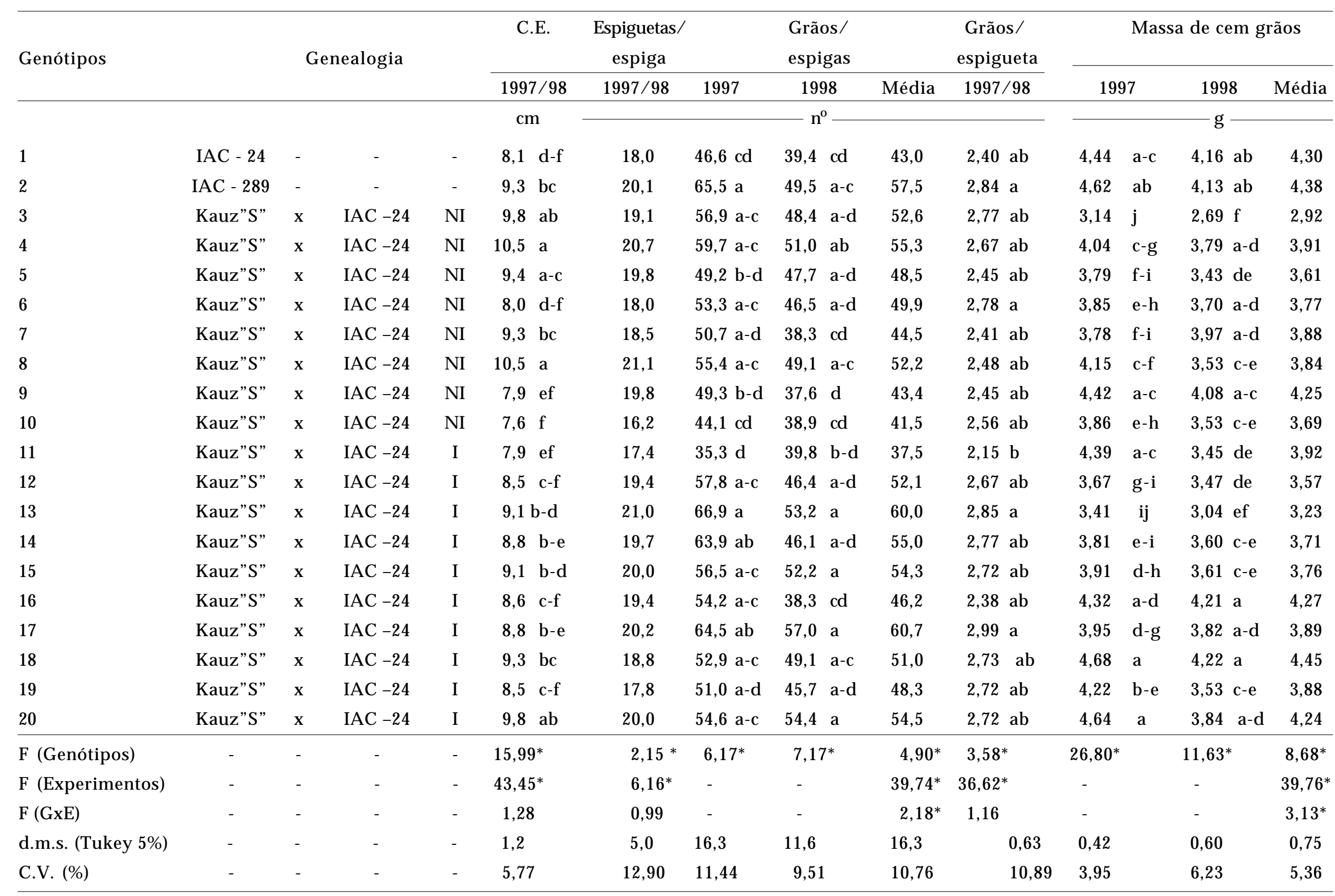

Significativo a 5\%; NI= Não irradiado e I= Irradiado. 
Tabela 7. Comprimento médio das raízes dos 20 genótipos de trigo avaliados nos Experimentos de Novas Linhagens Provenientes de Irradiação Gama, após 72 horas de crescimento em solução normal, que se seguiu a um crescimento em solução-tratamento contendo seis diferentes concentrações de alumínio (média de 2 repetições)

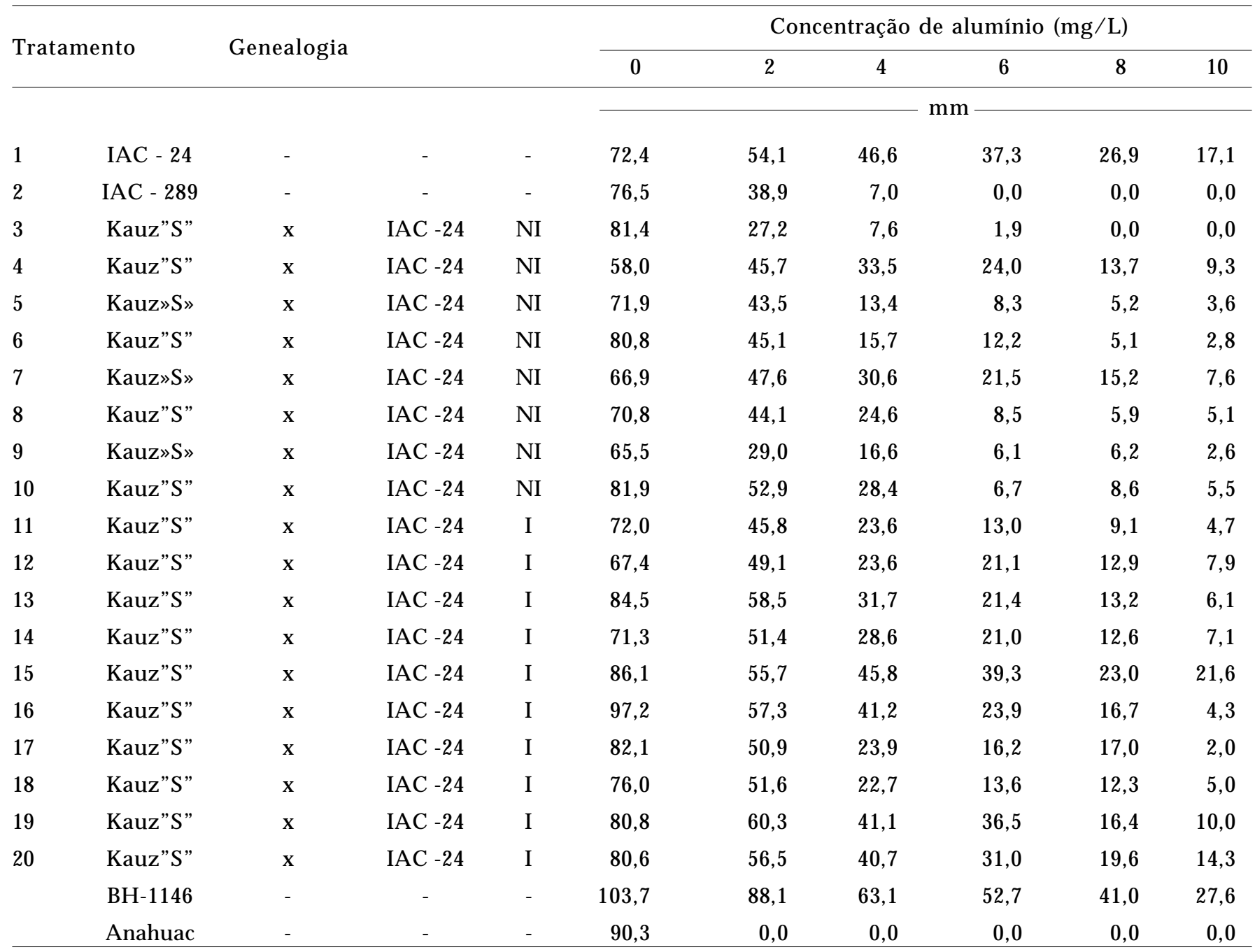

NI= Não irradiado e I= Irradiado.

Todos os genótipos avaliados foram tolerantes à presença de $10 \mathrm{mg} \mathrm{L}^{-1}$ de $\mathrm{Al}^{3+}$, isto é, apresentaram crescimento das raízes, após permanecerem 48 horas em soluções contendo $10 \mathrm{mg} \mathrm{L}^{-1}$ de $\mathrm{Al}^{3+}$, exceto a cultivar-controle Anahuac (sensível a $2 \mathrm{mg} . \mathrm{L}^{-1}$ de $\mathrm{Al}^{3+}$ ), a cultivar IAC-289 (sensível a $6 \mathrm{mg} \cdot \mathrm{L}^{-1}$ de $\mathrm{Al}^{3+}$ ) e a linhagem L3-NI (sensível a $8 \mathrm{mg} \cdot \mathrm{L}^{-1} \mathrm{de}^{-3+}$ ).

As correlações simples calculadas entre as produções médias de grãos dos 20 genótipos do experimento semeado em solo ácido de Capão Bonito e os comprimentos médios das raízes dos mesmos genótipos, medidos após 72 horas de crescimento na solução nutritiva, que se seguiu a crescimento na solução tratamento contendo 2 a $10 \mathrm{mg} \mathrm{L}^{-1}$ de $\mathrm{Al}^{3+}$, foram positivas e significativas, variando de 0,56 a
0,67 (dados não mostrados). Esses resultados foram confirmados considerando-se que a cultivar IAC-289, originária de linhagem introduzida do Centro Internacional de Melhoramento de Milho e Trigo (CIMMYT)/México, moderadamente sensível à toxicidade de $\mathrm{Al}^{3+}$ em soluções nutritivas. 'IAC289 'estava entre os genótipos mais produtivos em solos corrigidos (condição de sequeiro-Tietê ou de irrigação por aspersão-Tatuí) e entre os menos produtivos em solo ácido de Capão Bonito. Esses resultados também confirmam os obtidos por CAMARGO et al. (2003) e SALOMON et al (2003), sugerindo que os genótipos mais adaptados (mais produtivos) às condições de solo ácido e cultivo de sequeiro são tolerantes à toxicidade ao $\mathrm{Al}^{3+}$, em soluções nutritivas. 
Linhagens originárias por hibridações seguidas ou não de irradiação gama foram obtidas com características de resistência à ferrugem-da-folha e ao acamamento, com espigas compridas, maior número de grãos por espiga e por espigueta, maior massa de cem grãos e tolerância à toxicidade de $\mathrm{Al}^{3+}$.

O objetivo primário do programa de melhoramento de trigo do IAC é a liberação de novas cultivares. As seleções em todas as fases do programa de melhoramento, envolvendo o cruzamento Kauz "S"x IAC-24 foram realizadas sem que se soubessem a origem do material no que se refere ao tratamento (com ou sem irradiação gama nas sementes híbridas em geração $F_{2}$ ). Com o emprego de mutagênico associado à semente híbrida em geração $F_{2}$, além do efeito mutagênico na indução de mutantes para as características agronômicas de interesse, poderia também ocorrer um aumento na taxa de recombinação (BHATIA, 1977; WANG et. al 1986.; ZHEN et al., 1986; RAMESH, 1987; SAWHNEY, 1987). A característica básica utilizada para seleção foi sempre a produção. Esse aspecto é de importância, pois significa que se a irradiação pudesse ter facilitado a recombinação genética no cruzamento considerado e, portanto ampliado a variabilidade genética (maior precocidade ou menor altura de planta, por exemplo), tal fato poderia não ser detectado se o mutante não apresentasse alto potencial produtivo, pois o mesmo seria eliminado na seleção. Ainda que com essa "restrição", o estudo teria grande validade, pois mesmo dessa maneira como foi realizado, poderia se chegar à conclusão que a irradiação não deveria ser aplicada às sementes híbridas se seus efeitos fossem prejudiciais à obtenção de linhagens superiores (nesse caso não deveriam ser obtidas linhagens com boas características agronômicas nos tratamentos com irradiação).

Para os dois grupos, houve grande variabilidade nas linhagens desenvolvidas, no que se refere à produção de grãos, altura de plantas e outras características agronômicas, resistência às doenças e ao acamamento e, tolerância à toxicidade de alumínio. Esse fato confirma que linhagens com bom potencial foram obtidas por seleção nos dois grupos.

\section{CONCLUSÕES}

1. O emprego da técnica de indução de mutação associada à hibridação foi eficiente, tendo originado novos genótipos com características agronômicas desejáveis.

2. A linhagem L18-I destacou-se quanto à produção de grãos em condição de irrigação por aspersão e solo corrigido, nos três anos considerados. Em solo ácido e condição de sequeiro, a linhagem L20$\mathrm{I}$, tolerante à toxicidade de $\mathrm{Al}^{3+}$, em soluções nutritivas, destacou-se quanto à produção de grãos, diferindo somente da cultivar IAC-289, a mais sensível à toxicidade de $\mathrm{Al}^{3+}$. A cultivar IAC-289 e a linhagem L9-NI destacaram-se como as mais produtivas na condição de sequeiro e solo corrigido, diferindo somente de L3-NI e L11-I.

3. A linhagem L11-I, de porte mais baixo em todos os experimentos, associado à resistência ao acamamento e tolerância à toxicidade de $\mathrm{Al}^{3+}$, constituiu-se em fonte genética de valor para essas características, em programa de melhoramento genético. Todos os genótipos foram suscetíveis ao agente causal da mancha-da-folha. A linhagem L9-NI pela sua resistência à ferrugem-da-folha destacou-se por ser boa fonte em programas de melhoramento genético.

4. Com exceção das cultivares Anahuac e IAC289 e da linhagem L3-NI todos os genótipos avaliados foram tolerantes à presença de $10 \mathrm{mg} \mathrm{L}^{-1} \mathrm{de}^{\mathrm{Al}^{3+}} \mathrm{em}$ soluções nutritivas.

\section{AGRADECIMENTOS}

Os autores agradecem à Fundação de Amparo à Pesquisa do Estado de São Paulo (FAPESP) e à Agência Internacional de Energia Atômica (IAEA), Viena, Austria pelo apoio financeiro ao projeto, ao Conselho Nacional de Desenvolvimento Científico e Tecnológico (CNPq) e à FAPESP pela concessão de bolsas de produtividade científica e de mestrado, respectivamente.

\section{REFERÊNCIAS}

BATHIA, C.R. The use of mutagens for faciliting recombination. In: INTERNATIONAL ATOMIC ENERGY AGENCY. Manual on mutation breeding. Viena: IAEA, 1977. p.199.

CAMARGO, C.E.O. Melhoramento do trigo: VI. Hereditariedade da tolerância a três concentrações de alumínio em solução nutritiva. Bragantia, Campinas, v.43, p.279-291, 1984.

CAMARGO, C.E.O.; OLIVEIRA, O.F. Tolerância de cultivares de trigo a diferentes níveis de alumínio em solução nutritiva e no solo. Bragantia, Campinas, v.40, p.21-31, 1981.

CAMARGO, C.E.O.; FELICIO, J.C.; FERREIRA-FILHO, A.W.P.; BARROS, B.C.; PEREIRA, J.C.V.N.A.; PETTINELLI-JUNIOR, A. Comportamento agronômico de linhagens de trigo no Estado de São Paulo. Bragantia, Campinas, v.60, p.35-44, 2001. 
CAMARGO, C.E.O.; FELICIO, J.C.; FERREIRA-FILHO, A.W.P.; BARROS, B.C.; SABINO, J.C. Melhoramento do trigo: comportamento de novas linhagens em diferentes regiões do Estado de São Paulo. Arquivos do Instituto Biológico, São Paulo, v.61, p.16-27, 1994.

CAMARGO, C.E.O.; FELICIO, J.C.; TULMANN-NETO, A.; FERREIRA-FILHO, A. W.P.; PETTINELLI-JUNIOR, A.; CASTRO, J.L. Melhoramento de trigo: XXVIII. Novos genótipos obtidos por seleções em população segregante interespecífica submetida à irradiação gama. Bragantia, Campinas, v.54, p.5165, 1995.

CAMARGO, C.E.O.; FERREIRA-FILHO, A.W.P.; FREITAS, J.G. Avaliação de genótipos de centeio, triticale, trigo comum e trigo duro quanto à tolerância ao alumínio em solução nutritiva. Scientia Agricola, Piracicaba, v.55, p.227-232, 1998.

CAMARGO, C.E.O.; FERREIRA-FILHO, A.W.P.; RAMOS, L.C.S.; PETTINELLI-JUNIOR, A.; CASTRO, J.L.; FELICIO, J.C.; SALOMON, M.V.; MISTRO, J.C. Comportamento de linhagens diaplóides de trigo em dois locais do Estado de São Paulo. Bragantia, Campinas, v.62, p.217-226, 2003.

CAMARGO, C.E.O.; TULMANN-NETO, A.; FERREIRA-FILHO, A.W.P.; FELICIO, J.C. Genetic control of aluminum tolerance in mutant lines of the wheat cultivar Anahuac. Euphythica, Dordrecht, v.114, p.47-53, 2000.

CAMARGO, C.E.O.; TULMANN-NETO, A.; FERREIRA-FILHO, A.W.P.; FELICIO, J.C.; CASTRO, J.L..; PETTINELLI-JUNIOR, A. Novos genótipos de trigo (Triticum aestivum L.) obtidos por irradiação gama. Scientia Agricola, Piracicaba, v.54, p.195202, 1997.

MEHTA, Y.R. Doenças do trigo e seu controle. São Paulo: Agronômica Ceres, 1978. 190p.

MISTRO, J.C.; CAMARGO, C.E.O. Avaliação da produção de grãos e características agronômicas em genótipos de trigo, em 1999 e 2000. Bragantia, Campinas, v.61, p.35-42, 2002.

MOORE, D. P.; KRONSTAD, W. E.; METZGER, R. J. Screening wheat for aluminum tolerance. In: WORKSHOP ON PLANT ADAPTATION TO MINERAL STRESS IN PROBLEM SOILS, Beltsville, 1976. Proceedings... Ithaca: Cornell University, 1976. p.287-295.
RAMESH, B. Radiation effects on segregating seed in rice. Indian Journal of Botany, Hyderabad, v.10, p.17-20, 1987.

SALOMON, M.V.; CAMARGO, C.E.O.; FERREIRA-FILHO, A.W.P.; PETTINELLI-JUNIOR, A.; CASTRO, J.L. Desempenho de linhagens diaplóides de trigo obtidas via cultura de anteras quanto à tolerância ao alumínio, produção de grãos e altura de planta. Bragantia, Campinas, v.62, p.189-198, 2003.

SAWHNEY, R.N. Nuclear and allied approaches in improvement of wheat for disease and pest resistance. Journal of Nuclear Agriculture and Biology, New Dehli, v.16, p.109119,1987

SCHRAMM, W.; FULCO, W.S.; SOARES, M.H.G.; ALMEIDA, A. Resistência de cultivares de trigo em experimentação ou cultivo no Rio Grande do Sul, às principais doenças fúngicas. Agronomia Sulriograndense, Porto Alegre, v.10, p.31-52, 1974.

SIGURBJORSSON, B. Introduction: mutations in plant breeding programmes. In: INTERNATIONAL ATOMIC ENERGY AGENCY. Manual on mutation breeding. Viena: IAEA, 1977. p.1-6.

TULMANN-NETO, A.; CAMARGO, C. E.O.; ALVES, M.C.; SANTOS, R.R.; FREITAS, J.G. Indução de mutação visando obtenção de resistência às doenças no cultivar de trigo (Triticum aestivum L.) IAC-24. Pesquisa Agropecuária Brasileira, Brasília, v.30, p.497-504, 1995.

WANG, L.; FAN, O.; SHI, J.; WANG, Z. Induced mutations by irradiation of wheat hybrids. Mutation Breeding Newsletter, Viena, v.27, p.9, 1986.

ZHEN, Y.; SUN, G.; ZHANG, Y.; SHANG, Z. Breeding new disease resistant strains of wheat by using radiation and distant hybridization. Mutation Breeding Newsletter, Viena, v.27, p.7-9, 1986 